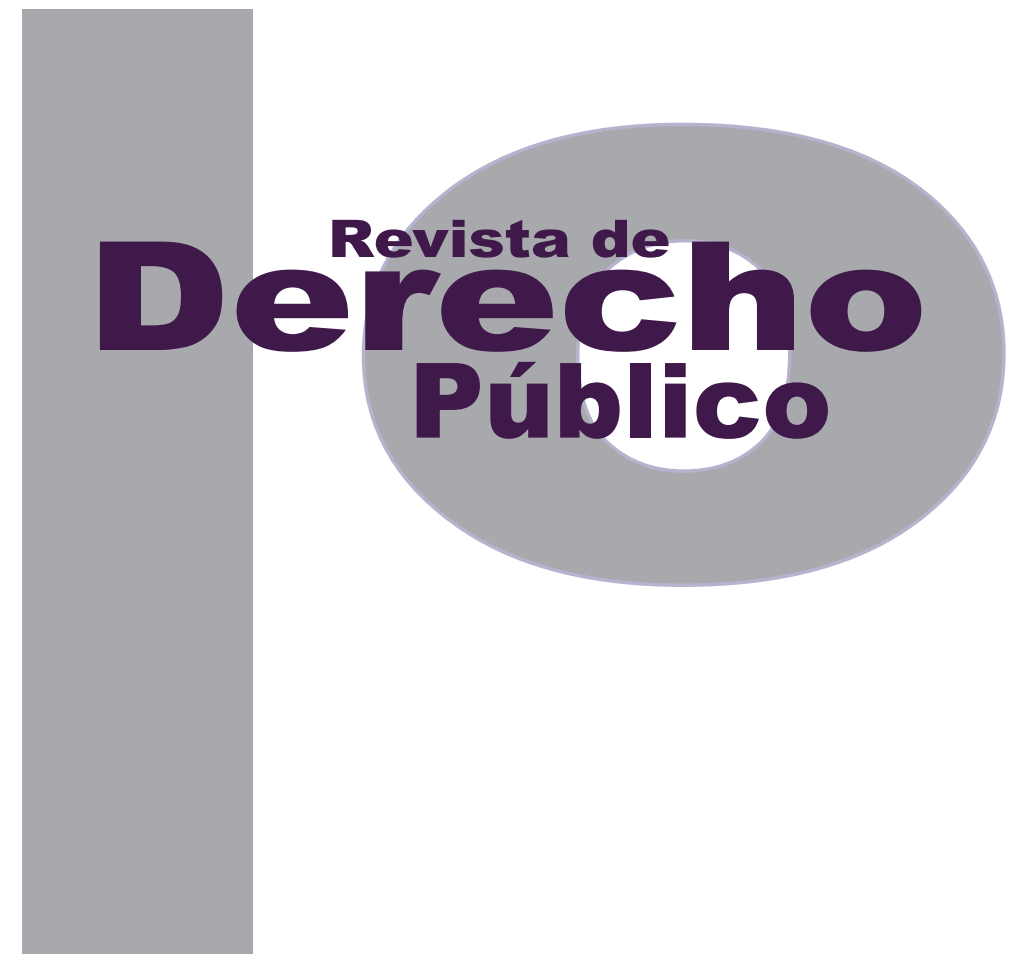

\title{
El AMPARO VerÁstegUI de 1849, LA PRIMERA DECISIÓN JUDICIAL DEL MECANISMO DE PROTECCIÓN INTEGRAL DE LOS DERECHOS FUNDAMENTALES
}

\author{
JuAN ANTONIO BARRERo BERARDINELLI
}

Universidad de los Andes

Facultad de Derecho

Revista de Derecho Público N. ${ }^{\circ} 29$

Julio - Diciembre de 2012. ISSN 1909-7778 


\title{
El Amparo Verástegui de 1849, la primera decisión judicial del mecanismo de protección integral de los derechos fundamentales
}

\author{
Juan Antonio Barrero Berardinelli*
}

\section{RESUMEN}

Este artículo explica el contexto histórico y la importancia jurídica de la primera decisión judicial impartida a través del juicio de amparo constitucional y resalta la influencia del amparo mexicano en el constitucionalismo moderno, en particular su injerencia en el desarrollo jurisprudencial de la acción de tutela colombiana. Consecuentemente, desde una perspectiva comparativa se analiza uno de los tópicos sobrevinientes de los mecanismos de protección de los derechos fundamentales que ha generado mayor controversia para la administración de justicia en Colombia: la procedencia de la acción de tutela contra providencias judiciales con efectos de cosa juzgada.

Palabras ClaVe: Derechos fundamentales, jurisprudencia constitucional, juicio de amparo, tutela contra providencias judiciales, cosa juzgada, tribunal constitucional, derecho comparado.
This article seeks to explain the historical context and the legal importance of the first ruling emitted through the application of the amparoconstitutional mechanism created in the nineteen century in Mexico to protect fundamental rights-. The article emphasizes its influence in modern constitutionalism and from a comparative view, also addresses one of the most controversial topics the Colombian justice administration currently faces; the admittance of a similar constitutional mechanism (the tutela) for the protection of fundamental rights when violated through rulings bearing Res Judicata effects.

KEY WORDS: Fundamental rights, constitutional court, constitutional jurisprudence, "amparo" constitutional mechanism, tutela constitutional mechanism, comparative law.

Abogado, Pontificia Universidad Javeriana. Especialista en Derecho Público, Universidad Sergio Arboleda. Máster en Administración Pública y Derechos Fundamentales, Universidad de Roma La Sapienza. Profesor de Derecho Público, Universidad de los Andes, Javeriana, Libre y Sergio Arboleda. Profesor invitado por la Universidad de Roma. Actualmente, magistrado auxiliar del Consejo Superior de la Judicatura. 


\section{SUMARIO}

Introducción - I. LA PRIMERA SENTENCIA DE AMPARO - II. LA ACCIÓN DE TUTELA - III. LA ACCIÓN DE TUTELA CONTRA PROVIDENCIAS JUDICIALES - IV. CONCLUSIÓN - Referencias. 
Introducción

Desde la expedición de la Constitución de 1991 ningún asunto ha suscitado tanta controversia como la procedencia excepcional de la acción de tutela contra providencias judiciales, posibilitada por vía jurisprudencial desde la emisión de la sentencia C-543 de 1992 que declaró inexequible el artículo 11 del Decreto 2591 de 1991. Al paso de dos décadas, en las que la Corte Constitucional ha defendido la prevalencia del derecho fundamental al debido proceso sobre el principio de la seguridad jurídica, se han formulado todo tipo de posturas a favor y en contra de esta medida, sin embargo, no se ha realizado un análisis del origen de esta institución; por ello, en el propósito de proporcionar elementos de juicio a la discusión resulta oportuno estudiar el andamiaje histórico que soporta este fenómeno judicial. En tal virtud, sin pretensión de hacer arqueología jurídica, lo cierto es que toda institución del derecho se ingenia con base en otras y es importante descifrar la genética de cada una o, mejor, desentrañar su verdadero linaje histórico, por lo cual en este escrito me referiré a la primera sentencia producida en el hemisferio, que de algún modo se aproximó a los puntos focales de la discusión, e intentaré desde una perspectiva comparativa relacionar la paradigmática pieza judicial con algunos precedentes de la Corte Constitucional colombiana.

\section{LA PRIMERA SENTENCIA DE} AMPARO

En la obra Los fundamentos de los derechos fundamentales, Ferrajoli (2007) formula una categórica distinción entre esquemas constitucionales que denomina formales y materiales. Los primeros son aquellos que no disponen de instrumentos efectivos para la protección de los derechos fundamentales, es decir, sistemas de derecho desprovistos de mecanismos procesales ágiles que los hagan valer y, por oposición, los segundos son aquellos que disponen de eficientes medios procesales tendientes a garantizar los derechos fundamentales que se consagran en la Carta Política.

Mucho antes de que en el ambiente del garantismo jurídico se formulara esta novísima categorización que hoy se respira de manera uniforme en la Unión Europea, la Constitución del estado de Yucatán, de 1841, fue pionera en la elaboración de la primera pieza procesal de protección integral de los derechos fundamentales -el amparo mexicano-, cuya confección se debe al jurista Manuel Crescencio García Rejón y Alcalá. A nivel nacional el juicio de amparo fue incorporado por vez primera en el Acta de Reformas de 1847, así:

[C]orresponde a este tribunal (la Corte Suprema de Justicia) reunido: $1^{\circ}$. Amparar en el goce de sus derechos a los que pidan su protección contra las providencias del Gobernador o Ejecutivo reunido, cuando en ellas se hubiese infringido el Código Fundamental o las leyes, limitándose en ambos casos a reparar el agravio en la parte que procediere.

Diez años más tarde, gracias a las reformas propuestas por Benito Juárez, el juicio de amparo fue consagrado en los artículos 101 y 102 de la Constitución Federal de 1857 y de manera definitiva, este formidable mecanismo procesal de 
protección integral de los derechos fundamentales, fue perfeccionado por la Constituyente de Querétaro en 1917, cuya carta política está próxima a cumplir un siglo de vigencia, y de donde sería tomado para múltiples ordenamientos jurídicos de Occidente.

Utilizo la expresión "mecanismo procesal de protección integral de los derechos fundamentales", ya que, en primer lugar, si bien el habeas corpus es primero cronológicamente hablando, pues evidentemente data de la Carta Magna de 1215, su espectro de protección solo contempla el derecho a la libertad y no otros derechos fundamentales. En segundo lugar, la judicial review norteamericana, aunque permite inaplicar una determinada disposición normativa frente a un caso particular, provee un esquema mucho más artificial -al contraerse simplemente a inaplicar una disposición de manera abstracta-, que el procedimiento in concreto mexicano que imparte la protección directa de los derechos fundamentales.

En tratándose del recurso de amparo alemán es necesario precisar que, si bien este forjó su propia historia pues registra antecedentes innegables en la tradición germánica, no obstante, ello es de manera indirecta, puesto que no fue en su acepción actual ${ }^{2}$, como sí ocurrió desde la primera mitad del siglo XIX y a nivel nacional en México, además, porque las instituciones jurídicas no existen por su invención, si no, por su

2 El artículo 93 de la Ley Fundamental de Bonn establece que al Tribunal Constitucional corresponde decidir: “... sobre los recursos de amparo que pueden ser interpuestos por toda persona que se crea lesionada por el poder público en uno de sus derechos fundamentales o en uno de sus derechos contenidos en los artículos 20, apartado 4, $33,38,101,103$ y $104 . "$ constante utilización. A este respecto, el recurso de amparo alemán tiene su antecedente más remoto en el Reichskammergericht del Sacro Imperio Romano Germánico (962-1806), que permitía a los súbditos presentar queja ante el emperador con el fin de obtener protección. Desaparecido el imperio en el año 1806, la Constitución local del Estado de Baviera de 1818 facultó a los ciudadanos para que interpusieran un recurso ante la Asamblea de Clases, por la violación de sus derechos constitucionales. Posteriormente, la primera Constitución a nivel nacional $^{3}$, que fue la de la Iglesia de San Pablo de Frankfurt, de 1849, dispuso de un mecanismo de impugnación para que los ciudadanos demandaran ante el Reichsgericht la violación de sus derechos, pero esta Constitución nunca entró en vigor, pues el Estado alemán solo se unificó hasta el año 1871.

Correspondió entonces a la Constitución Estatal de Baviera de 1919, "Constitución de Bamberg", la consagración del instrumento jurídico de protección de los derechos fundamentales más próximo a la acepción actual. Por virtud del artículo 93 de dicha Constitución, los ciudadanos estaban facultados para acudir al Tribunal Estatal Staatsgerichtshof, cuando la actuación de alguna autoridad violara sus derechos. Si bien la Constitución de la República de Weimar de 1919 previó una jurisdicción constitucional, no tuvo mayor significación, ya que su desarro-

3 A nivel nacional Alemania solo ha tenido tres constituciones: la Constitución de la Iglesia de San Pablo de Frankfurt de 1849, que a pesar de no haber entrado en vigor, tiene importancia como modelo histórico, especialmente en relación con la teoría de los derechos fundamentales; la segunda Constitución fue la de Weimar de 1919; y, por último, la Ley Fundamental de Bonn de 1949 que a la fecha ha sido reformada en 54 ocasiones. 
llo se empañó con la aplicación del artículo 484, a través del cual se adoptaron las medidas de emergencia que permitieron la instauración de un régimen totalitario; precisamente por ello implicó un enorme retroceso en materia de derechos fundamentales. De modo tal, que solo hasta la expedición de la Ley Fundamental de Bonn de 1949 se consagró de manera expresa el recurso de amparo y, por ende, sería a partir del funcionamiento del Tribunal Constitucional Federal en 1951 cuando se puso en práctica este instrumento.

Pues bien, regresando al juicio de amparo mexicano, aunque no existe unanimidad de criterios en cuanto a cuál fue la primera sentencia de amparo que se produjo, la gran mayoría de tratadistas, así como la propia Suprema Corte de Justicia de esa nación (Arizpe, 2009), coinciden en que se trata del amparo fallado el 13 de agosto de 1849 por el entonces Juzgado Único del Distrito de San Luis Potosi ${ }^{5}$ (González,

$4 \quad$ Artículo 48. Si la seguridad y el orden público al interior del Reich son severamente dañados o están en peligro, el presidente del Reich podrá tomar las medidas necesarias que lleven a restablecer el orden, interviniendo con la asistencia de las fuerzas armadas, de ser necesario. Para este propósito, podrá suspender temporalmente, totalmente o en parte, los derechos fundamentales proveídos en los artículos 114, $115,117,118,123,124$ y 153

El presidente del Reich debe informar al Reichstag sin demora sobre todas las medidas tomadas de acuerdo con los párrafos 1 y 2 de este artículo. Estas medidas pueden ser revocadas a petición del Reichstag.

Si el peligro es inminente, el Gobierno del Estado puede tomar medidas temporales para su propio territorio, como lo provee el párrafo 2. Estas medidas pueden ser revocadas a petición del Reichstag.

Los detalles serán determinados por una ley del Reich.

5 Amparo a un rebelde. La primera sentencia de un juicio de amparo. Manuel González Oropeza, en Revista del Instituto de la Judicatura Federal. Sentencia contenida en la obra de Enrique Arizpe Narro: La primera sentencia de amparo. Presentación de Mariano Azuela Güitrón, México, Suprema Corte de Justicia de la Nación, 2006, 69 páginas. 45-48: "San Luis Potosí, agosto 13 de 1849. Visto el antecedente dictamen y teniendo presente que el artículo 25 de la Acta de Reformas, impone al juzgado de mi cargo la obligación de amparar a cual-
2006). Los hechos que dieron lugar a tan histórica decisión fueron los siguientes:

El 2 de febrero de 1848 los gobiernos de los Estados Unidos Mexicanos y los Estados Unidos de Norteamérica suscribieron el Tratado de Guadalupe-Hidalgo, que puso fin a un conflicto armado surgido entre ambos países, y como consecuencia del cual, se fijó una nueva línea fronteriza en el río Bravo, lo que implicó que gran parte del te-

quier ciudadano contra los ataques violentos, ya sea de los supremos poderes de la nación, ya de los Estados: que la circunstancia de no haberse reglamentado el modo y términos en que tal protección debe dispensarse, no es ni puede ser un obstáculo para cumplir con ese sagrado deber, porque a nadie puede ocultarse el modo de sustanciar un expediente y que, de no dar cumplimiento al citado artículo, resultaría una contravención del objeto y fin que los legisladores se propusieron, no menos que una muy notable infracción, que inconcusamente Manuel González Oropeza haría responsable al que la cometiera; que una ley desde el momento que se publica debe ser obligatoria; no expresándose en ella lo contrario, como dice no se ha podido ni puede dejar de cumplir con la referida disposición constitucional, a pesar de las razones que expresa el Sr. Gobernador del Estado en la comunicación que dirigió a este juzgado el 4 del corriente por conducto de su secretaría, por no ser suficientes para no observar lo que manda la ley con objeto de proteger las garantías individuales, y siendo como es cierto que el mismo Sr. Gobernador expidió contra D. Manuel Verástegui la orden de destierro que motivó el ocurso que ha dado lugar a la formación de las antecedentes actuaciones, contraviniendo a lo dispuesto por el supremo gobierno de la Unión a consecuencia de la ley de 24 de abril del corriente año, y cometiendo un verdadero ataque a las garantías individuales que deben respetarse siempre por cualquiera autoridad, por estar afianzadas en la Constitución y ser esto conforme al buen orden y comunal provecho de la sociedad; por tales fundamentos y demás que se contienen en el precitado dictamen a que me refiero, se declara que este juzgado dispensa a D. Manuel Verástegui la protección que solicita, en conformidad de lo dispuesto en el repetido artículo 25 del Acta de Reformas para que no pueda ser desterrado del Estado, sin que proceda la formación del juicio y pronunciamiento del fallo por la autoridad judicial a que exclusivamente corresponde por la Constitución; debiendo quedar entre tanto en el pleno uso de sus derechos y libertad que la misma Carta fundamental le concede como ciudadano mexicano. Comuníquese esta disposición al interesado para su inteligencia, dándole copia testimoniada de ella si la pidiere.- Hágase igual comunicación por medio de la correspondiente nota al supremo gobierno del Estado, para el debido acatamiento de este fallo y sus efectos, manifestándole a la vez que el juzgado en manera alguna espera se le obligue a usar los recursos que la ley ha puesto en sus manos para hacer respetar y cumplir sus disposiciones, estando como se halla dispuesto a conservar la dignidad de este tribunal, y hacer que sus fallos sean debidamente respetados, y dese cuenta con todo al Supremo Gobierno de la Unión para los efectos que hubiere lugar. EI Sr. D. Pedro Zámano, primer suplente del juzgado de Distrito en actual ejercicio por ausencia del propietario, así lo decretó, mandó y firmó por ante mí, de que doy fe.- Pedro Zámano. Manuel de Arriola." 
rritorio mexicano pasara al dominio anglosajón: California, Nevada, Utah, Nuevo México, Texas, así como otras extensas zonas se convirtieron en territorio estadounidense. Como era previsible, una decisión tal produjo levantamientos armados en varios estados, fraguados por movimientos nacionalistas que se resistieron a la pérdida del territorio mexicano. En San Luis Potosí surgió la llamada Rebelión de Sierra Gorda, de la que hizo parte Manuel Verástegui, quien se encargó de redactar el plan en que se apoyó la insurrección. Por su participación en ese movimiento, Verástegui fue detenido y trasladado a la capital del estado, en donde estuvo privado de la libertad aproximadamente un mes.

Sin embargo, el general Julián de los Reyes, gobernador de San Luis Potosí, a quien se pretendía derrocar con los actos de insurrección, ordenó dejar en libertad a Verástegui, pero, condicionó su liberación a que este abandonara el Estado. Inconforme con la orden de destierro, Verástegui promovió un juicio de amparo contra la decisión, ante el entonces Juzgado Único del Distrito de San Luis Potosí, que para entonces estaba a cargo del juez Pedro Zámano, quien en calidad de suplente por ausencia del titular del despacho, dictó fallo el 13 de agosto de 1849.

La providencia judicial dictada por el Juzgado de San Luis Potosí se fundamentó en que la orden de destierro vulneraba las garantías individuales previstas en la Constitución y, en consecuencia, concedió protección en favor del accionante Manuel Verástegui, disponiendo en la parte resolutiva que se revocara la orden de destierro proferida por el gobernador del estado. Como era de esperarse, la sentencia fue apelada por el gobernador del estado de San Luis Potosí, ante lo cual, la Suprema Corte de Justicia de los Estados Unidos Mexicanos confirmó en todas sus partes la providencia emanada del despacho del juez Zámano.

Más allá de constituir la primera sentencia de amparo, lo que per se merece resaltarse, la decisión resumida contiene tres puntos esenciales, a saber: (i) se concede el amparo en contra de la orden de destierro, argumentando que constituye una vulneración de las garantías individuales consagradas a nivel constitucional, dando así aplicación a la Constitución por sobre toda otra norma; (ii) se determina la aplicación del artículo 25 del Acta de Reformas de 1847, es decir, de un precepto enunciado en la Constitución Federal cuyo procedimiento aún no se había reglamentado, haciendo prevalecer lo sustancial sobre lo formal6; y (iii) se trata de una acción constitucional dirigida contra una decisión que para entonces podía catalogarse como judicial por contener una sanción penal.

[y] siendo como es cierto que el mismo Sr. Gobernador expidió contra D. Manuel Verástegui la orden de destierro que motivó el ocurso que ha dado lugar a la formación de las antecedentes actuaciones, contraviniendo a lo dispuesto por el supremo gobierno de la Unión a consecuencia de la ley de 24 de abril del corriente año, y cometiendo un verdadero ataque a las

6 Para entender mejor la importancia de esta consideración jurídica es importante señalar que solo hasta el siglo XXI, la Corte Constitucional colombiana consolidó una línea jurisprudencial basada en el exceso ritual manifiesto y que está conformada por las siguientes sentencias de constitucionalidad y de tutela: C-334 de 2000, T-382 de 2001, C-646 de 2002, T-289 de 2005, T-1091 de 2008, T-052 de 2009, T-264 de 2009. 
garantías individuales que deben respetarse siempre por cualquier autoridad, por estar afianzadas en la Constitución y ser esto conforme al buen orden y comunal provecho de la sociedad; por tales fundamentos y demás que se contienen en el precitado dictamen a que me refiero, se declara que este juzgado dispensa a D. Manuel Verástegui la protección que solicita, en conformidad de lo dispuesto en el repetido artículo 25 del Acta de Reformas para que no pueda ser desterrado del Estado, sin que proceda la formación del juicio y pronunciamiento del fallo por la autoridad judicial a que exclusivamente corresponde por la Constitución; debiendo quedar entre tanto en el pleno uso de sus derechos y libertad que la misma Carta fundamental le concede como ciudadano mexicano. (Suprema Corte de Justicia de los Estados Unidos Mejicanos, 1848, fallo Verástegui).

En el segundo punto de los enunciados se encuentra el problema jurídico principal, que consistía en una verdadera laguna legislativa de primer nivel, ya que el mecanismo de amparo estaba consagrado en la Constitución, pero no existía una norma que reglamentara la materia y ni siquiera se sabía cuál era el procedimiento que se debía seguir o cuál era el juez competente para conocer de la causa (la primera Ley de Amparo se expidió en 1861).

De tal suerte que el aporte, menos que cronológico, concierne a una gran concepción humana, ajena al contexto de una época universalmente marcada por el legalismo y el formalismo jurídico y, precisamente por ello, merece ser analizado desde su verdadero punto de partida. En este orden de consideraciones, para comprender mejor el espíritu que impulsó la creación de este revolucionario instrumento, es necesario conocer la ingeniería mental de su artífice, el filósofo jurista mexicano Manuel Crescencio Rejón, quien antes de crear el amparo para la Constitución yucateca de 1841 propuso ante el parlamento mexicano medidas tales como la abolición de la pena de muerte, por considerarla contraria a la humanidad y, en ese mismo sendero, solicitó que se prohibiera toda forma de discriminación en contra de los indígenas. Ello, en mi criterio, revela el origen hispánico de sus ideas, no solo porque el respeto por los pueblos aborígenes tiene nítidos antecedentes en las ideas asentadas en esta parte del hemisferio por el padre Fray Bartolomé de las Casas en época de la colonia -las cuales permitieron el mestizaje-, sino, además, porque procesalmente el juicio de amparo tiene raíces en el amparo colonial de las Leyes de Indias, recopiladas en 1681, que rigieron en el Virreinato de la Nueva España (México) y cuyos ancestros más remotos, seguramente se remontan a las garantías previstas en el Fuero Juzgo de Castilla de 1241 y las Siete Partidas compiladas durante el reinado de Alfonso X, El Sabio, que fueron promulgadas en 1348.

Toda institución del derecho se ingenia con base en otras, y es un gravísimo error pensar que la historia de las nuestras comenzó con la vida republicana, como si por virtud de la independencia hubiese desaparecido todo el legado jurídico; las instituciones coloniales desarrolladas durante tres siglos no necesariamente desaparecieron con la vida republicana, por el contrario, se mantuvieron y dieron forma a las nuevas. No obstante, al abordar este delicado punto, es 
un deber señalar que en torno al origen del juicio de amparo existe abundante discusión en la doctrina. De una parte, hay quienes sostienen que proviene de pleno de la revisión judicial norteamericana, fundamentándose para ello en la influencia ejercida por los federalist papers en el constitucionalismo latinoamericano, lo que en mi criterio es bastante desacertado, ya que si se revisa, en la configuración de las instituciones mexicanas es posible evidenciar elementos autóctonos desde los levantamientos de Hidalgo y Morelos y, en tal sentido, no necesariamente tuvieron por modelo las ideas de la ilustración o del consecuente proceso constitucionalizador de Filadelfia, este último sí tuvo por base espiritual los planteamientos elaborados por Hamilton, Jay y Madison en los federalist papers.

De otra parte, están los que consideran que se trata de una institución con clarísimos precursores en el amparo colonial proveniente de Castilla y de Aragón. Al respecto, Malagón Pinzón (2003, vol. 5), citando al historiador Andrés Lira Guillén, dice lo siguiente:

[e]l historiador Andrés Lira Guillén, al hacer un estudio de estos casos, y de otros similares, esboza la existencia de un amparo colonial. Esta institución tenía por objeto la protección de: las personas en sus derechos cuando éstos son alterados o violados por agraviantes que realizan actos injustos de acuerdo con el orden jurídico existente y conforme al cual una autoridad protectora, el virrey, conociendo directamente, o indirectamente como presidente de la Real Audiencia de México, de la demanda del quejoso agraviado, sabe la responsabilidad del agraviante y los daños actuales y o futuros que se siguen para el agraviado, y dicta el man- damiento de amparo para protegerlo frente a la violación de sus derechos, sin determinar en éste la titularidad de los derechos violados, y solo con el fin de protegerlos en la violación.

Finalmente están los que reconocen un proceso de hibridación entre la judicial review y el amparo colonial, entre quienes se encuentra uno de los más autorizados tratadistas del derecho procesal constitucional, el insigne profesor Héctor Fix Samudio (1992):

[e]sta institución, la más importante del derecho procesal mexicano, se creó después de una lenta y a veces atormentada evolución, en la cual se combinaron influencias externas con el desarrollo de instrumentos consagrados en documentos constitucionales mexicanos. El resultado fue un instrumento híbrido, resultado del trasplante de una institución norteamericana, perteneciente a la familia o tradición del common law, en un procedimiento inspirado en la legislación hispánica, situada en la familia o tradición continental europea, de origen romano-canónico. Por otra parte, una vez consolidado, el amparo mexicano sufrió transformaciones esenciales que modificaron de manera sustancial su estructura procesal.

Si pasamos breve revista a los antecedentes externos, descubrimos, en primer término, la influencia del derecho constitucional de los Estados Unidos, tanto por lo que se refiere al habeas corpus de origen británico, consagrado en las diversas constituciones de las antiguas colonias inglesas, como especialmente la revisión judicial de la constitucionalidad de las leyes (judicial review), tal como fue descrito en el clásico libro del tratadista francés Alexis de Tocqueville, La democracia en América del Norte, cuya traducción castellana de Sánchez 
de Bustamante, aparecida en París en el año de 1836, fue conocida ampliamente por los juristas y políticos mexicanos de la época.

Pero la denominación deriva de la tradición hispánica, en virtud de que el nombre de amparo, considerado como "castizo, evocador y legendario", de acuerdo con la certera frase del conocido constitucionalista mexicano Felipe Tena Ramírez, se inspira en dos instituciones del mismo nombre, que se originan tanto en el derecho castellano, que era el aplicable en las colonias españolas en América (además de las llamadas Leyes de Indias), como en los procesos forales aragoneses, en ambos casos como instrumentos protectores de los derechos de los gobernados.

Al margen de la discusión relativa al origen, considero que lo realmente importante es la vanguardia de las ideas propuestas por García Rejón, las cuales dan cuenta de una inconmensurable concepción humana que, por fortuna, tuvo desarrollo sostenido en el constitucionalismo mexicano y anteceden por mucho la tardía filosofía ius naturalista que se acuñó en Europa solo hasta después de la Segunda Guerra Mundial, para pedirle perdón a la humanidad. Con lo que el mérito es aún mayor, si se tiene en cuenta que México padeció con mayor rigor la influencia del legalismo, como consecuencia de la invasión francesa que permitió la instauración del gobierno déspota de Maximiliano I, Emperador de México entre 1864 y 1867.

Ahora bien, según se mencionó atrás, en la doctrina no existe acuerdo en torno a cuál fue el primer juicio de amparo. Al respecto, es importante señalar que Manuel González Oropeza
(2006) publicó un artículo titulado: El primer juicio de amparo sustanciado en México, en el que sostiene que el primero no fue el amparo Verástegui, sino el amparo García Torres promovido por el editor Vicente García Torres en 1847, en procura del derecho fundamental a la libertad de prensa, por hechos relacionados con críticas que este publicó en el periódico Monitor Republicano, en las que censuraba al general Santa Anna -para entonces Presidente- por la derrota militar y la consecuente firma del tratado que reconoció la separación de Texas. De igual forma, sostiene que hubo al menos cinco decisiones judiciales anteriores al caso Verástegui. La razón por la que en este escrito establezco el amparo Verástegui como primer referente jurisprudencial, radica en que la Suprema Corte de Justicia de México lo reconoce como tal, por tanto, oficialmente es esa la decisión judicial a la que se le concede dicho mérito y, en todo caso, de no ser la primera pues siempre habrá lugar a que surjan documentos que cambien la historia-, al menos, el amparo Verástegui, por su carga argumentativa y su consistencia lógica, me atrevo a afirmar, sin temor a equívocos, que es la decisión más interesante de esa época.

Durante la segunda mitad del siglo XIX el juicio de amparo se consolidó jurisprudencialmente, lo que facilitó su pronta vigorización, a tal punto que, a inicios del siglo XX, valiéndome de una expresión acuñada por Yepes Arcila (2009): "la Constitución es tributaria del ambiente en el que nace", la Revolución Mejicana iniciada en 1910 se convirtió en el escenario de reclamación que permitió a la Constituyente de Queréta- 
ro de 1917 reconocer y proteger vía amparo los derechos sociales. Si se compara, en el entorno europeo surgieron, prácticamente de manera simultánea, con la expedición de la Constitución de Weimar de 1919, pero solo fueron exigibles hasta 1977 cuando el jurista checoslovaco Karel Vasac los categorizó como derechos de segunda generación, lo que por demás, sirvió para que se aglomeraran en las constituciones contemporáneas bajo la denominación de derechos de contenido económico, social y cultural(DESC).

En el siglo XX se ampliaron los supuestos para la procedencia del juicio de amparo, en especial, a partir de la expedición de la Ley de Amparo de 1936, reglamentaria de los artículos 103 y 107 de la Constitución de Querétaro, se consagraron diversas modalidades del juicio, a saber: (i) para la protección de la libertad personal; (ii) para demandar leyes contrarias a la constitución; (iii) para atacar los actos de la administración; (iv) para proteger los derechos sociales ${ }^{7}$, y (v) como mecanismo de impugnación contra

$7 \quad$ Ley de Amparo, reglamentaria de los artículos 103 y 107 de la Constitución Política de los Estado Unidos Mexicanos. Artículo 212.- Con la finalidad de tutelar a los núcleos de población ejidal o comunal y a los ejidatarios y comuneros en sus derechos agrarios, así como, en su pretensión de derechos, a quienes pertenezcan a la clase campesina, se observarán las disposiciones del presente Libro Segundo en los siguientes juicios de amparo:

I.- Aquéllos en que se reclamen actos que tengan o puedan tener como consecuencia privar de la propiedad o de la posesión y disfrute de sus tierras, aguas, pastos y montes a los ejidos, o a los núcleos de población que de hecho y por derecho guarden el estado comunal, o a los ejidatarios o comuneros, lo mismo si las entidades o individuos mencionados figuran como quejosos que como terceros perjudicados.

II.- Cuando los actos reclamados afecten o puedan afectar otros derechos agrarios de las entidades o individuos a que se refiere la fracción anterior, sea que figuren como quejosos o como terceros perjudicados.

III.- Aquéllos en que la consecuencia sea no reconocerles o afectarles en cualquier forma derechos que hayan demandado ante las autoridades, quienes los hayan hecho valer como aspirantes a ejidatarios o comuneros. providencias judiciales $^{8}$. Lo que acudiendo a la expresión utilizada por el profesor Fix Samudio (1992) lo convierte en "una federación de instrumentos procesales en la que cada uno posee una función tutelar específica."

Como se puede verificar entonces, se trata de un instituto de prospectiva universal y como tal su desarrollo ha sido exponencial; innumerables constelaciones jurídicas lo han replicado con idéntica finalidad, pero, mediante un trato procesal diferente: mientras que en México es un juicio, en Alemania y en Bolivia es un recurso, en España es un proceso sustantivo independiente, en Brasil es un mandato de seguridad, en Argentina es una acción procesal y en Colombia es una acción de tutela. Probablemente, el caso más interesante es el uruguayo en el que siendo una acción, ésta no está prevista en la Constitución, pero surge de una interpretación de la misma. A nivel supranacional también está consagrado por cuenta del recurso previsto en el artículo 25.1 de la Convención Americana sobre Derechos Humanos, que se interpone ante la Corte Interamericana y que ha sido bautizado como el amparo interamericano.

Por todo lo dicho, considero que el veredicto de la historia debe ser justo, y así como al buen pueblo de Virginia y a los forjadores de la Revolución Francesa se les reconoce el mérito histórico de haber confeccionado el primer catálogo

8 Ley de Amparo, reglamentaria de los artículos 103 y 107 de la Constitución Política de los Estados Unidos Mexicanos. Artículo 44.- El amparo contra sentencias definitivas o laudos, sea que la violación se cometa durante el procedimiento o en la sentencia misma, o contra resoluciones que pongan fin al juicio, se promoverá por conducto de la autoridad responsable, la que procederá en los términos señalados en los artículos 167, 168 y 169 de esta ley. 
de derechos humanos, al constituyente mexicano debe reconocérsele el mérito de la invención, implantación y puesta en funcionamiento de la técnica general del procedimiento constitucional que los hace valer.

\section{LA ACCIÓN DE TUTELA}

En segundo lugar quiero referirme de manera muy puntual a la tardía pero muy afortunada acción de tutela colombiana, cuya confección debemos al constituyente Juan Carlos Esguerra Portocarrero (2007) y que, desde luego, como todo mecanismo de amparo, se deriva de la invención mexicana. Digo tardía, ya que luego de la iniciativa mexicana, en el entorno latinoamericano surgió un repertorio de instrumentos con diversas técnicas procesales: la República de El Salvador fue la primera en adoptarlo en el año 1886, Honduras y Nicaragua hicieron lo propio en 1894, Argentina y Guatemala en 1921, Panamá en 1941, Costa Rica en 1949, Venezuela en 1961, Bolivia y Paraguay en 1967, Perú en 1979 y Uruguay en 1984.

Tal vez por una excesiva influencia de la tradición jurídica francesa el amparo arribó tan tarde a Colombia, sin embargo, al ser tan reciente se trata de un instrumento de última tecnología jurídica, cuya mejor descripción la hizo el profesor alemán Mathias Heldeger (2010): “La acción de tutela es una creación autóctona colombiana en la que confluyen elementos del habeas corpus, del juicio de amparo y de la excepción de inconstitucionalidad lo que la convierte en un instrumento sui generis del derecho constitucional."
Pues bien, sobre la acción de tutela se han escrito cualquier cantidad de tratados que ocupan bibliotecas enteras y, precisamente por ello, solo me detendré para hacer dos planteamientos puntuales, relacionados con las consideraciones jurídicas del fallo mexicano en estudio. El primero, para hacer una crítica a la restricción prevista en el artículo 85 de la Constitución de 1991, disposición en la que por sugerencia del constituyente Augusto Ramírez Ocampo equívocamente fueron clasificados los derechos humanos de acuerdo con su grado de exigibilidad $^{9}$, en aquellos que taxativamente son de aplicación inmediata y aquellos a la intemperie de los poderes públicos, es decir, de no aplicación inmediata. Lo que constituye una antinomia constitucional, en la medida en que algo, por elemental lógica aristotélica, no puede ser y no ser a la vez. En otras palabras, los derechos o son fundamentales $y$, por tanto, se pueden proteger a través del mecanismo de amparo, o simplemente no lo son, pero no pueden serlo y no serlo de manera simultánea.

Ante esta enorme barrera -pues si se revisa, derechos como la salud y la educación quedaron por fuera del espectro de protección del artículo en estudio-, la Corte Constitucional colombiana, tempranamente con la sentencia T-002 de 1992, construyó la doctrina de la conexidad según la cual, cuando un derecho de no aplicación inmediata pende de otro de aplicación inmediata se hace fundamental por conexidad y, por ende, merece protección por vía de tutela.

\footnotetext{
$9 \quad$ Artículo 85. Son de aplicación inmediata los derechos consagrados en los artículos 11, 12, 13, 14, 15, 16, 17, 18, 19, 20, 21, 23, 24, 26, 27, $28,29,30,31,33,34,37$ y 40 .
} 
Se trata de un invaluable precedente judicial que, en su momento, sirvió para hacerle un quite a la muralla prevista en el mencionado artículo 85 y que posteriormente fue confirmado por innumerables sentencias, siendo una de las más estudiadas, la T-406 de 1992, en la que, con ocasión de la deficiente construcción de un acueducto fueron vulnerados los derechos a la salubridad pública y al medio ambiente sano de los habitantes de un barrio de Cartagena (Bolívar). En principio, los derechos a la salubridad y al ambiente sano son amparables por vía de las acciones populares previstas para la protección de derechos de tipo colectivo, cuya reglamentación solo se efectuó hasta la expedición de la Ley 472 de 1998. Así, para la época de los hechos no existía una regulación que los amparara, sin embargo, ante la inminente vulneración de derechos, la Corte Constitucional aprovechó para pronunciarse en los siguientes términos:

[e]l carácter de fundamental no coincide con el de aplicación inmediata. Siendo así, es necesario distinguir entre derechos fundamentales de aplicación inmediata y derechos fundamentales que no son de aplicación inmediata. Ante esta dificultad, corresponde a la jurisprudencia, y en especial a la Corte Constitucional, la definición de la naturaleza y alcance de los derechos fundamentales que no son de aplicación inmediata. (Corte Constitucional T-406, 1992).

Para luego señalar de manera categórica que:

[e]xiste una nueva estrategia para el logro de la efectividad de los derechos fundamentales. La coherencia y la sabiduría de la interpretación y, sobre todo, la eficacia de los derechos fundamentales en la Constitución de 1991, están asegurados por la Corte Constitucional.
Esta nueva relación entre derechos fundamentales y jueces significa un cambio fundamental en relación con la Constitución anterior; dicho cambio puede ser definido como una nueva estrategia encaminada al logro de la eficacia de los derechos, que consiste en otorgarle de manera prioritaria al juez, y no ya a la administración o al legislador, la responsabilidad de la eficacia de los derechos fundamentales. En el sistema anterior la eficacia de los derechos fundamentales terminaba reduciéndose a su fuerza simbólica. Hoy, con la nueva Constitución, los derechos son aquello que los jueces dicen a través de las sentencias de tutela. (Corte Constitucional T-406, 1992).

Si se revisa, la sentencia T-406 de 1992 toca el punto más álgido de la discusión, esto es, el rol que cumplen las ramas del poder público ${ }^{10}$ y la permanente tensión que se ocasiona con la posible invasión de su ámbito competencial, de lo cual surge una pregunta inevitable: ¿debe el juez esperar a que el legislador desarrolle una materia necesaria para impartir protección de derechos que hacen parte de la condición humana o debe el juez decidir sin la existencia de tal reglamentación? Nótese, que se trata del mismo problema jurídico que debió afrontar el juez Zámano cuando decidió el caso Verástegui en 1849.

10 "[L]a doctrina de la separación de poderes ha variado sustancialmente en relación con la formulación inicial. Aquello que en un principio tenía como punto esencial la separación de los órganos, cada uno de ellos depositario de funciones bien delimitadas, ha pasado a ser, en la democracia constitucional actual, una separación de ámbitos funcionales dotados de un control activo entre ellos. Lo dicho está en acuerdo, además, con una interpretación contemporánea de la separación de los poderes, a partir de la cual el juez pueda convertirse en un instrumento de presión frente al legislador, de tal manera que este, si no desea ver su espacio de decisión invadido por otros órganos, adopte las responsabilidades de desarrollo legal que le corresponden y expida las normas del caso. Este contrapeso de poderes, que emergen de la dinámica institucional, es la mejor garantía de la protección efectiva de los derechos de los asociados." (Sentencia T-406 de 1992, Corte Constitucional). 
Frente a este problema que se sitúa en un campo delicadísimo, considero que el estado de necesidad de los usuarios de la justicia hace que la discusión sea tan innecesaria como superflua, pues no importa cuál rama del poder proporcione aquello que es inherente a la condición humana, lo importante es que lo haga. Este planteamiento desde luego deviene de la realidad como fuente imperativa de derecho diritto vivente.

También es preciso señalar que en un segundo momento, para superar las limitaciones impuestas por el artículo 85, la Corte Constitucional a efectos de interpretar el alcance de los derechos fundamentales, abordó la distinción entre principios y reglas constitucionales desarrollada principalmente por la jurisprudencia alemana, a partir del fallo Lüth de 1958, por virtud del cual el Tribunal Constitucional Federal revocó una decisión de la jurisdicción ordinaria que condenó al director de la Academia de Prensa de Hamburgo, Erich Lüth, al pago de los perjuicios ocasionados al cineasta Veit Harlan, por haber boicoteado una película tildada de contener propaganda antisemita. El fundamento jurídico que permitió desmontar la providencia judicial es el efecto irradiador $^{11}$ de los derechos fundamentales ${ }^{12}$ :

11 Desde la Sentencia C-239 de 1997, la Corte Constitucional se fundamenta en el efecto irradiador: "La Constitución establece que el Estado colombiano está fundado en el respeto a la dignidad de la persona humana; esto significa que, como valor supremo, la dignidad irradia el conjunto de derechos fundamentales reconocidos, los cuales encuentran en el libre desarrollo de la personalidad su máxima expresión. El principio de la dignidad humana atiende necesariamente a la superación de la persona, respetando en todo momento su autonomía e identidad".

12 Para profundizar sobre este tema es posible revisar la obra de Dietter Grimm, quien considera que el efecto del fallo es que los derechos fundamentales pasan a constituir un orden objetivo de valores. Dieter, G. (2006). Constitucionalismo y Derechos Fundamentales. Madrid: Editorial Trotta.
[I]a Ley Fundamental, que no quiere ser un orden neutral de valores, ha establecido también en la parte dedicada a los derechos fundamentales un orden objetivo de valores y que precisamente con ello se pone de manifiesto un fortalecimiento por principio de la pretensión de validez de los derechos fundamentales. Este sistema de valores, que encuentra su núcleo en la personalidad humana que se desarrolla libremente en el interior de la comunidad social y en su dignidad, debe regir, en tanto que decisión constitucional básica, en todos los ámbitos del derecho; la legislación, la administración y la jurisprudencia reciben de él directrices e impulso. (Tribunal Constitucional Federal Alemán, 1958, fallo Lüth).

De acuerdo con lo anterior, los impulsos producidos por el compuesto de principios estructurados en forma de derechos fundamentales tienen un ámbito de aplicación tan expansivo, que terminan por influir todas las áreas de la juridicidad -llegan hasta donde tienen que llegar- 0 , en otros términos, producen un efecto dominó sobre todas las esferas del derecho, con un perímetro de acción que, al parecer, solo alcanza a ser delimitado por la jurisprudencia, a tal punto que surten efectos a priori frente a las relaciones entre particulares, lo que ha sido denominado por la jurisprudencia del Tribunal Constitucional Federal Alemán, como la "eficacia horizontal de los derechos fundamentales" (Estrada, 2000). Y en tal sentido logran derribar, incluso, el efecto de la cosa juzgada de la jurisdicción ordinaria:

[I]a dignidad del ser humano y el libre desarrollo de la personalidad (la cual se desenvuelve en el interior de una comunidad social) forman el núcleo de este sistema de valores, el cual 
constituye, a su vez, una decisión jurídicoconstitucional fundamental, válida para todas las esferas del derecho. Así, este sistema de valores aporta directivas e impulsos al poder legislativo, a la administración y a la judicatura. Este influye, por supuesto, también al Derecho Civil: ninguna disposición del Derecho Civil puede estar en contradicción con él; todas deben interpretarse en su espíritu. El contenido jurídico de los derechos fundamentales como normas objetivas se desarrolla en el Derecho Privado a través de las disposiciones que predominan directamente en medio de ese campo del Derecho. Así como el nuevo derecho debe estar en concordancia con el sistema de valores fundamental, el viejo Derecho [anterior a la Constitución] debe orientarse -en cuanto a su contenido- a ese sistema de valores. De ahí se deriva para él un contenido constitucional específico que determina de ahora en adelante su interpretación. (Tribunal Constitucional Federal Alemán, 1958, fallo Lüth).

Esta consideración jurídica conduce al segundo planteamiento, relacionado con lo que continúa siendo uno de los tópicos más controversiales para la administración de justicia en Colombia, esto es, la procedencia de la acción de tutela contra providencias judiciales, como ya se dijo, viabilizada por vía interpretativa desde la sentencia C-543 de 1992, en lo que ya dejó de ser un simple choque de trenes para convertirse en un verdadero choque de galaxias.

\section{LA ACCIÓN DE TUTELA CONTRA PROVIDENIAS JUDICIALES}

En el plano del derecho comparado los mecanismos de amparo contra decisiones judiciales no suscitan mayor controversia ni generan tanta incertidumbre jurídica. En efecto, en México ${ }^{13}$, país precursor de la tutela, desde la expedición de la Ley de Amparo de 1936 está prevista una modalidad específica de amparo contra providencias judiciales, pero limitada por una subregla según la cual es improcedente contra decisiones judiciales de la Suprema Corte de Justicia: "Artículo 73.- El juicio de amparo es improcedente: I.- Contra actos de la Suprema Corte de Justicia ${ }^{14} ;$ (...)". En Alemania, el contenido dispositivo del numeral $4^{\circ}$ del artículo 19 de la Ley Fundamental de 1949 dispone que: "Toda persona cuyos derechos sean vulnerados por el poder público, podrá recurrir a la vía judicial." Lo que ha servido para que los jueces admitan su procedencia.

En Panamá el recurso de amparo procede contra providencias judiciales, de conformidad con lo dispuesto en el artículo 50 de la Constitución de 1972:

Artículo 50. Toda persona contra la cual se expida o se ejecute, por cualquier servidor público, una orden de hacer o no hacer, que viole los derechos y garantías que esta Constitución consagra, tendrá derecho a que la orden sea revocada a petición suya o de cualquiera persona. El recurso de amparo de garantías constitucionales a que este artículo se refiere, se tramitará mediante procedimiento sumario y será de competencia de los tribunales judiciales.

13 También es importante señalar que, actualmente, en el parlamento mexicano cursa una reforma constitucional que se propone modificar de manera integral el juicio de amparo.

14 Ley de Amparo, reglamentaria de los artículos 103 y 107 de la Constitución Política de los Estados Unidos Mexicanos. 
Sin embargo, al igual que en México, es improcedente contra los fallos dictados por la Corte Suprema de Justicia, por prohibición expresa del artículo 204 de la Constitución: "Artículo 204. No se admitirán recursos de inconstitucionalidad ni de amparo de garantías constitucionales contra los fallos de Corte Suprema de Justicia ó sus Salas."

En España, es posible por cuenta de lo dispuesto en el artículo 44 de la Ley Orgánica/2 de 1979:

Artículo 44. Uno. Las violaciones de los derechos y libertades susceptibles de amparo constitucional, que tuvieran su origen inmediato y directo en un acto $u$ omisión de un órgano judicial, podrán dar lugar a este recurso siempre que se cumplan los requisitos siguientes: $A$. Que se hayan agotado todos los medios de impugnación previstos por las normas procesales para el caso concreto dentro de la vía judicial. B. Que la violación del derecho o libertad sea imputable de modo inmediato y directo a una acción u omisión del órgano judicial con independencia de los hechos que dieron lugar al proceso en que aquellas se produjeron, acerca de los que, en ningún caso, entrará a conocer el Tribunal Constitucional. C. Que se haya denunciado formalmente en el proceso, si hubo oportunidad, la vulneración del derecho constitucional tan pronto como, una vez conocida, hubiera lugar para ello.

Pero, lo anterior tiene un término perentorio en atención a lo dispuesto en el numeral segundo del mismo artículo; debe interponerse en el término máximo de 30 días: "Dos. El plazo para interponer el recurso de amparo será de 30 días, a partir de la notificación de la resolución recaída en el proceso judicial."
En Venezuela, la acción de amparo procede contra providencias, desde la expedición del artículo $4^{\circ}$ de la Ley Orgánica de Amparo sobre Derechos y Garantías Constitucionales de 1987 y, actualmente, por virtud del artículo 25 de la Constitución de 1999: "Todo acto dictado en ejercicio del Poder Público que viole o menoscabe los deberes garantizados por esta Constitución y la ley es nulo, y los funcionarios públicos y funcionarias públicas que lo ordenen o ejecuten incurren en responsabilidad penal, civil y administrativa, según los casos, sin que les sirva de excusa órdenes superiores."

En Brasil el mandato de seguridad procede contra decisiones judiciales como consecuencia de lo previsto en el artículo 108 de la Constitución de 1988: "Es competencia de los Tribunales Regionales Federales: ... 3. Ios "mandados de seguranca" y los "habeas data" contra actos del propio Tribunal o de los jueces federales".

Como atrás se dijo, en Colombia el Decreto 2591 de 1991, que tiene origen en las facultades extraordinarias concedidas por virtud del artículo $5^{\circ}$ transitorio de la Constitución de 1991, reglamentó la acción de tutela y dispuso de manera expresa su procedencia contra providencias judiciales, lo que vía acción pública de inconstitucionalidad fue declarado inexequible por la Corte Constitucional, mediante la sentencia C-543 de 1992, bajo la idea de que se pone en entredicho el efecto de la cosa juzgada y, por tanto, se atenta contra la seguridad jurídica. Pero, a su vez, la sentencia en cita abrió un orificio para la procedencia excepcional de la tutela contra providencias judiciales ${ }^{15}$ : “No procede la acción de

15 La que ha sido desarrollada por las sentencias T-639 de 2005, C-590 de 2005, T-805 de 2005, T-958 de 2005, T-358 de 2007, entre otras que consolidan esa línea jurisprudencial. 
tutela contra ninguna providencia judicial, con la única salvedad del perjuicio irremediable" (Corte Constitucional, C-543, 1992), es decir, ante la ocurrencia de una vía de hecho ${ }^{16}$, hoy rebautizadas como causales genéricas de procedibilidad de la acción de tutela contra providencias judiciales ${ }^{17}$.

Esta postura ha sido defendida por la Corte Constitucional mediante la expedición de una artillería de autos ${ }^{18}$ que obligan a los jueces, de cualquier instancia y jurisdicción, a conocer nuevamente las acciones de tutela cuando son rechazadas de plano por otras autoridades judiciales $^{19}$, que inobservan que, al igual que el

16 En la sentencia T-231 de 1994 la Corte Constitucional se pronunció en los siguientes términos: "[S]i este comportamiento -abultadamente deformado respecto del postulado en la norma- se traduce en la utilización de un poder concedido al juez por el ordenamiento para un fin no previsto en la disposición (defecto sustantivo), o en el ejercicio de la atribución por un órgano que no es su titular (defecto orgánico), o en la aplicación del derecho sin contar con el apoyo de los hechos determinantes del supuesto legal (defecto fáctico), o en la actuación por fuera del procedimiento establecido (defecto procedimental), esta sustancial carencia de poder o de desviación del otorgado por la ley, como reveladores de una manifiesta desconexión entre la voluntad del ordenamiento y la del funcionario judicial, aparejará su descalificación como acto judicial."

17 (i) defecto sustantivo, ver sentencia T-300 de 2010; (ii) defecto procedimental, ver sentencia T-268 de 2010; (iii) defecto orgánico, ver sentencia T-313 de 2010; (iv) defecto fáctico, ver sentencia T-808 de 2006; (v) error inducido o defecto por consecuencia, ver sentencia T-1094 de 2007; (vi) decisión sin motivación, ver sentencias T-302 de 2008 y 868 de 2009; (vii) desconocimiento del precedente constitucional, ver sentencia T-482 de 2011; (viii) violación directa de la Constitución, ver sentencia T-747 de 2009.

Ver auto 004 de 2004 y auto 100 de 2008 de la Corte Constitucional.

19 Ello en cumplimiento de sus dos grandes funciones: (i) el control abstracto de constitucionalidad que comprende la revisión de constitucionalidad de las normas que se encuentran o pretenden ingresar al ordenamiento en los estrictos y precisos términos de los numerales 1 , 2, 3, 4, 5, 7, 8 y 10 del artículo 241 de la Constitución y, sobre todo, del (ii) control concreto de constitucionalidad que consiste en la protección de los derechos fundamentales y cuya revisión está reservada a la Corte Constitucional, de conformidad con el mandato contenido en el numeral $9^{\circ}$ del artículo 241 constitucional. Así, cuando los jueces fallan las tutelas, se transforman o mejor sufren una formidable metamorfosis, ya que transitoriamente abandonan su respectiva jurisdicción para convertirse en jueces constitucionales y, en consecuencia y por analo- artículo 19 de la Ley Fundamental de Bonn, el artículo 86 de la Constitución de 1991 establece de manera expresa que toda persona podrá reclamar sus derechos por vía de tutela: “(...) cuando quiera que estos resulten vulnerados o amenazados por la acción o la omisión de cualquier autoridad pública." Es decir, toda autoridad pública incluye a los jueces.

\section{CONCLUSIÓN}

Al margen de la inevitable y perpetua tensión existente entre el efecto de la cosa juzgada y el derecho fundamental al debido proceso, tal vez todo este panorama histórico conduzca a dos conclusiones generales: de una parte, que el nudo problemático que se ha querido hacer ver, se presente menos por la fundamentación jurídica que permite la procedencia de la tutela contra providencias judiciales y más por la arquitectura inapropiada de un sistema plurijurisdiccional, en el que operan cuatro cortes de cierre que no se resisten la supremacía de la una sobre la otra y, de otra, no deja de ser asombroso y paradójico que, si en el entorno latinoamericano desde 1849 se produjo un razonable precedente contra providencia judicial, con un exponencial desarrollo en innumerables constelaciones de ambos hemisferios, aún cueste tanto comprender la fundamentación jurídica que lo permite. 


\section{Referencias}

Brewer, C. (2008). Reflexiones sobre la Revolución Norteamericana (1776), la Revolución Francesa (1789) y la Revolución Hispanoamericana (1810-1830 y sus aportes al Constitucionalismo Moderno. Bogotá: Universidad Externado.

Bustillos, J. (2008). El amparo directo en México. México: Editorial Porrúa.

CAstro, J. (2005). Las partes en el juicio de amparo. México: Fondo de Cultura Económica.

Dieter, G. (2006). Constitucionalismo y Derechos Fundamentales. Madrid: Editorial Trotta.

Eastman, J. (1991). Constituciones políticas comparadas de América del Sur. Bogotá: Parlamento Andino.

EsGuerRA, J. (2007). La protección constitucional del ciudadano. Bogotá: Editorial Legis.

Estrada, J.A. (2000). La eficacia de los derechos fundamentales entre particulares. Bogotá: Universidad Externado de Colombia.

Ferrajoli, L. (2009). Principia luris. Teoría del derecho y de la democracia. Madrid: Editorial Trotta.

Ferrajol Luigi. (2007). Los fundamentos de los derechos fundamentales. Madrid: Editorial Trotta.

Fioravanti, M. (2007). Los derechos fundamentales. Madrid: Editorial Trotta.
Ferrer, M. E, y Zaldívar, L. A. (2009). Coordinadores Académicos. La ciencia del derecho procesal constitucional. Estudios en homenaje a Héctor Fix Samudio. Bogotá: Temis.

Fix Samudio, H. (1992). El juicio de amparo mexicano y el recurso constitucional federal alemán. Breves reflexiones comparativas. Asociación unam. Revista de Derecho Comparado. Núm. 77.

González, C. A. (1985). El juicio de amparo. México: Editorial Porrúa.

Malagón Pinzón, M. A. (2008). Vivir en Policía: una contralectura de los orígenes del derecho administrativo. Bogotá: Universidad Externado.

Morales, A. J. (2006). La acción de tutela en Alemania y en Colombia. Bogotá: Editorial Ibañez-Hans Seidel Stiftung.

Vallarta, I. (1881). El juicio de amparo y el Writ of Habeas Corpus: ensayo crítico-comparativo sobre esos recursos constitucionales. México: Imprenta de Francisco Díaz de León.

VIDAL, P. J. (2007). Introducción al control constitucional. Bogotá: Ediciones Academia CoIombiana de Jurisprudencia.

ZACCARIA, G. (2007). La giurisprudenza come fonte di diritto. Un'evoluzione storica e teorica. Napoli: Universita Degli Studi Suor Orsola Benincasa, Facoltá Giurisprudenza.

Zagrebelsky, G. (1995). El derecho dúctil, ley, derechos, justicia. Madrid: Trota. 


\section{Sentencias}

Alemania. Tribunal Constitucional Federal Alemán. (1958). Fallo Lüth.

Colombia. Corte Constitucional. T-002, T-406/1992, C-543/19992 C-334/2000, T-382/2001, C-646/2002, T-289/2005, C-590/2005, T-639 de 2005, T-805 de 2005, T-958 de 2005, T-808 de 2006,
C-239/2007, T-358/007, T-747 de 2009, T-1094 de 2007, T-302 de 2008, T-1091/2008, T-052/2009, T-264/2009, T-868 de 2009, T-268 de 2010,T- 300 de 2010, T-313 de 2010, T-482 de 2011.

México. Suprema Corte de Justicia de los Estados Unidos Mexicanos. (1848). Fallo Verástegui. 